J. Craig Hartman PhD, Paul S. Pagel MD, Lester T. Proctor MD, John P. Kampine MD PhD, William T. Schmeling MD PhD, David C. Warltier MD PhD

\title{
Influence of desflurane, isoflurane and halothane on regional tissue perfusion in dogs
}

The actions of desflurane, isoflurane and halothane on regional tissue perfusion were studied using radioactive microspheres in dogs chronically instrumented for measurement of arterial and left ventricular pressure, global (left ventricular $d P / d t_{\max }$ ) and regional (percent segment shortening) contractile function, and diastolic coronary blood flow velocity. Systemic and coronary haemodynamics and regional tissue perfusion were measured in the conscious state and during anaesthesia with equihypotensive concentrations of desflurane, isoflurane, and halothane. All three volatile anaesthetics $(P<0.05)$ increased heart rate and decreased mean arterial pressure, left ventricular systolic pressure, and left ventricular $d P / d t_{\max }$ Myocardial perfusion was unchanged in subendocardial, midmyocardial, and subepicardial regions by the administration of either dose of desflurane. No redistribution of intramyocardial blood flow (endo/epi ratio) was observed during desflurane anaesthesia. Although regional myocardial perfusion was reduced $(P<0.05)$ in a dose-related

\section{Key words}

ANAESTHETICS, VOLATILE: desflurane (1653), halothane, isoflurane;

HEART: coronary blood flow;

KIDNEY: blood flow;

LIVER: blood flow;

DUODENUM: blood flow;

MUSCLE SKELETAL: blood flow;

MEASUREMENT TECHNIQUES: microspheres.

From the Departments of Anesthesiology, Pharmacology and Medicine, Medical College of Wisconsin, Milwaukee,

Wisconsin, and the Zablocki Veterans Administration Medical Center, Milwaukee, Wisconsin.

Supported in part by USPHS grant HL 36144, VA Medical Research Funds, and Anesthesiology Research Training Grant GM 08377.

Address correspondence to: Dr. David C. Warltier, Medical College of Wisconsin, MFRC A1000, 8701 W. Watertown

Plank Road, Milwaukee, Wisconsin 53226.

Accepted for publication 18th May, 1992. fashion by halothane and by isoflurane at high concentrations, redistribution of intramyocardial blood flow was not observed during halothane or isoflurane anaesthesia. All three volatile anaesthetics reduced blood flow to the renal cortex, but only desflurane produced a decrease in renal cortical vascular resistance. Hepatic blood flow decreased in response to halothane but not desflurane or isoflurane. Concomitant decreases in hepatic resistance were observed during administration of desflurane and isoflurane. Dose-related decreases in intestinal and skeletal muscle blood flow were observed during halothane and isoflurane but not desflurane anaesthesia. The results suggest that desflurane maintains myocardial, hepatic, intestinal, and skeletal muscle blood flow while halothane and isoflurane decrease regional tissue perfusion in these vascular beds to varying degrees during systemic hypotension in the chronically instrumented dog.

Ce travail étudie les effets du desflurane, de l'isoflurane et de l'halothane sur la perfusion régionale à l'aide de microsphères radioactives sur des chiens préparés à demeure pour mesures itératives de la tension artérielle et ventriculaire gauche, de la contractilité globale (dP/dt $t_{\max }$ ventriculaire gauche) et régionale (index de raccourcissement segmentaire) ainsi que de la vélocité du débit coronarien diastolique. L'hémodynamique systémique et coronaire et la perfusion régionale ont été mesurées à l'état de conscience et pendant l'anesthésie avec des concentrations hypotensives équivalentes de desflurane, d'isoflurane et d'halothane. Les trois agents $(P<0,05)$ ont augmenté la fréquence cardiaque et diminué la tension artérielle moyenne et le $d P / d t_{\max }$ ventriculaire gauche. La perfusion myocardique est demeurée inchangée aux régions subendocardique, midendocardique et subépicardique pendant l'administration de desflurane. On n'observe pas de redistribution du débit intramyocardique (rapport endo./épi.) pendant l'anesthésie au desflurane. Bien que la perfusion régionale soit réduite $(P<0,05)$ de façon proportionnelle pour les concentrations élevées d'isoflurane et d'halothane, la redistribution de débit sanguin myocardique n'est pas observée pendant l'anesthésie avec ces agents. Alors que les trois agents volatils diminuent le débit sanguin au cortex rénal, seul le desflurane en diminue la résistance vasculaire. Le débit sanguin hépatique diminue sous halothane mais non sous 
isoflurane et desflurane. Une diminution simultanée des résistances hépatiques survient pendant l'administration de desflurane et d'isoflurane. Des baisses de débit sanguin à l'intestin et aux muscles squelettiques proportionnelles à la concentration sont observées pendant l'anesthésie à l'halothane et l'isoflurane mais ne surviennent pas sous desflurane. Ces résultats suggèrent le maintien par le desflurane des débits sanguins myocardique, hépatique, intestinal et musculaire alors que l'halothane et l'isoflurane diminuent la perfusion tissulaire régionale de ces lits vasculaires à différents degrés pendant l'hypotension systémique chez le chien.

The systemic haemodynamic effects of a new inhalational anaesthetic, desflurane (1653), have recently been characterized in experimental animals ${ }^{1-4}$ and in man. ${ }^{5-7}$ A structural analogue of isoflurane, desflurane produces increases in heart rate and dose-dependent decreases in arterial pressure, systemic vascular resistance, and myocardial contractility while preserving cardiac output in vivo. In addition to producing a haemodynamic profile which is very similar to isoflurane, desflurane offers several biophysical characteristics that make this volatile anaesthetic attractive for clinical use: a low blood gas partition coefficient facilitating rapid induction and emergence, ${ }^{8}$ minimal metabolic breakdown, ${ }^{9.10}$ and little end-organ toxicity. ${ }^{11,12}$

The effects of desflurane on regional myocardial perfusion have only been partially described. Two recent investigations $\mathrm{s}^{2,3}$ suggested that desflurane, like isoflurane, may produce coronary artery vasodilatation, a finding which may be theoretically associated with a decrease in collateral flow to ischaemic myocardium during an increase in blood flow to normal zones ("coronary steal"). The precise actions of desflurane on the distribution of myocardial perfusion in normal coronary vasculature has not been defined. However, a recent investigation from this laboratory ${ }^{13}$ demonstrated that desflurane did not alter the regional distribution of coronary blood flow in a canine model of multivessel coronary artery obstruction. In addition, although volatile anaesthetics, including desflurane, uniformly reduce arterial pressure, the capacity of these agents to alter tissue blood flow to various organs is also dependent on the direct and indirect influences of each anaesthetic on vascular smooth muscle in specific tissue beds. Few studies ${ }^{2.4}$ to date have examined the impact of desflurane on regional blood flow or the distribution of cardiac output. Therefore, the current investigation was undertaken to examine systematically the effects of desflurane on regional tissue perfusion in the heart, kidney, liver, intestine and skeletal muscle and compare these effects to those produced by isoflurane and halothane. Radionuclide-labelled microspheres were used in chronically instrumented dogs to characterize regional blood flow to these organs. Anaesthetics were delivered in equally hypotensive doses, providing equivalent reductions in driving pressure and allowing comparisons of the direct actions of these agents on regional tissue perfusion independent of perfusion pressure.

\section{Methods}

\section{Implantation of instruments}

All experimental procedures and protocols in this investigation were reviewed and approved by the Animal Care Committee of the Medical College of Wisconsin. Furthermore, all conformed to the Guiding Principles in The Care and Use of Animals of the American Physiologic Society and were accordance with the Guide for the Care and Use of Laboratory Animals. *

Conditioned mongrel dogs of either sex weighing between 20 and $30 \mathrm{~kg}$ were fasted overnight. Anaesthesia was induced with sodium thiamylal $\left(10 \mathrm{mg} \cdot \mathrm{kg}^{-1}\right.$, iv) and after tracheal intubation, anaesthesia was maintained with halothane $(1.0$ to $1.5 \%)$ in $100 \%$ oxygen $\left(1 \mathrm{~L} \cdot \mathrm{min}^{-1}\right)$ via positive pressure ventilation. Under sterile conditions, a thoracotomy was performed in the left fifth intercostal space and the lung gently retracted. Heparin-filled catheters were placed in the thoracic aorta and the right atrial appendage for measurement of arterial pressure and for fluid or drug administration, respectively. A catheter was placed in the left atrial appendage for measurement of left atrial pressure and for administration of radioactive microspheres used in the determination of regional tissue blood flow. A 1.5 to $2.0 \mathrm{~cm}$ segment of the proximal left anterior descending coronary artery (distal to the first diagonal branch) was isolated and a precalibrated Doppler ultrasonic flow transducer $(20 \mathrm{mHz})$ was placed around this vessel for measurement of diastolic coronary blood flow velocity. A high-fidelity, miniature micromanometer (Konigsberg Instruments, Pasadena, CA, Model P7) was implanted in the apex of the left ventricle for measurement of continuous left ventricular pressure. The left ventricular micromanometer was cross-calibrated in vivo against pressures measured via left ventricular, aortic and left atrial catheters (Gould, Oxnard, CA, Model P50). The maximum rate of rise of left ventricular pressure (peak positive $\mathrm{dP} / \mathrm{dt}$ ), an index of global left ventricular contractility, was obtained by electronic differentiation of the left ventricular pressure waveform. A pair of miniature ultrasonic segment length transducers ( $5 \mathrm{MHz}$ ) for measurement of changes in regional contractile function

*Department of Health, Education, and Welfare (Division of Health and Human Services): Guide for the Care and Use of Laboratory Animals. DHEW (DHHS) publication no. (NIH) 85-23, revised 1985. 
(percent segment shortening) were implanted within the left ventricular subendocardium (10-15 mm apart and 7-9 $\mathrm{mm}$ deep) in a circumferential plane in the perfusion territory of the left anterior descending coronary artery. All instrumentation was secured, tunneled beneath the scapulae and exteriorized via several small incisions. The chest wall was closed in layers and pneumothorax evacuated by a chest tube. Each dog was fitted with a jacket (Alice King Chatham, Los Angeles, CA) to prevent damage to the instruments and catheters which were housed in an aluminum box within the jacket pocket.

After surgery, each dog was treated with analgesics (buprenorphine $\left(0.02 \mathrm{mg} \cdot \mathrm{kg}^{-1}, \mathrm{im}\right)$ ) as needed. Antibiotic prophylaxis consisted of procaine penicillin $G(25,000$ $\left.\mathrm{U} \cdot \mathrm{kg}^{-1} \mathrm{im}\right)$ and dihydrostreptomycin $\left(20 \mathrm{mg} \cdot \mathrm{kg}^{-1} \mathrm{im}\right)$. Dogs were allowed to recover for a minimum of seven to ten days before experimentation. During the postoperative period, dogs were trained to stand quietly in a sling during haemodynamic monitoring. Segment length and coronary blood flow velocity signals were driven and monitored by ultrasonic amplifiers (Hartley, Houston, TX). End systolic segment length (ESL) was determined at maximum negative left ventricular $\mathrm{dP} / \mathrm{dt}$, and end diastolic segment length (EDL) was determined prior to the onset of left ventricular isovolumetric contraction. The lengths were normalized according to the method described by Theroux et al..$^{14}$ Percent segment shortening (\%SS) was calculated by the use of the equation: \%SS $=($ EDL-ESL) $\times$ 100/EDL. Relative diastolic coronary vascular resistance was calculated as the quotient of diastolic arterial pressure and diastolic coronary blood flow velocity $\left(\mathrm{Hz} \times 10^{2}\right)$. All haemodynamic data were continuously recorded on a polygraph (Hewlett-Packard, San Francisco, CA, model 7758A) and digitized via a computer interfaced with an analogue to digital convertor.

\section{Regional tissue perfusion}

Carbonized plastic microspheres (New England Nuclear, Boston, MA; $15 \pm 2 \mu \mathrm{m}$ diameter) labelled with ${ }^{141} \mathrm{Ce}$, ${ }^{103} \mathrm{Ru},{ }^{51} \mathrm{Cr}$ or ${ }^{95} \mathrm{Nb}$ were used to measure regional tissue perfusion. ${ }^{15}$ Immediately before injection, the sphere suspension was ultrasonicated (E/MC Corporation, Model 450) for $15 \mathrm{~min}$ and agitated in a vortex mixer (ColeParmer, Model 4722) for five minutes. The microsphere injection consisted of approximately 2 to $3 \times 10^{6}$ spheres injected into the left atrial chamber as a bolus over ten seconds and flushed in with $10 \mathrm{ml}$ of warm $\left(37^{\circ} \mathrm{C}\right)$ saline. A few seconds before each microsphere injection, a timed collection of reference arterial blood was initiated and maintained at a constant rate of $7 \mathrm{ml} \cdot \mathrm{min}^{-1}$ for three minutes (precalibrated Harvard infusion/withdrawal pump, Model 1941).

At the conclusion of each experiment, transmural myocardial tissue samples were selected from the anterior left ventricular free wall for mapping of regional myocardial blood flow. The samples were subdivided into subepicardial, midmyocardial and subendocardial layers of approximately equal thickness. Multiple tissue samples were also obtained from the cortex of the left kidney, lower left lobe of the liver, proximal third of the duodenum and skeletal muscle of the neck. The tissue samples were weighed, placed in scintillation vials and the activity of each isotope determined. The activity of each isotope in the reference blood flow sample was also determined. The radioactivity in the tissue and reference blood flow samples were analyzed with a gamma counter (Minaxi 5000, Packard, Downers Grove, IL). Tissue blood flow $\dot{\mathrm{Q}}_{\mathrm{m}} ; \mathrm{ml} \cdot \mathrm{min}^{-1} \cdot \mathrm{g}^{-1}$ ) was calculated from the equation: $\dot{\mathrm{Q}}_{\mathrm{m}}=$ $\dot{Q}_{r} \cdot C_{m} / C_{r}$, where $\dot{Q}_{r}=$ rate of withdrawal of the reference blood flow sample $(\mathrm{ml} / \mathrm{min}), C_{r}=$ activity (counts per minute, cpm) of the reference blood flow sample, and $\mathrm{C}_{\mathrm{m}}$ $=$ activity $\left(\mathrm{cpm} \cdot \mathrm{g}^{-1}\right)$ of the tissue sample. Relative tissue vascular resistance for each vascular bed was calculated as the quotient of mean arterial pressure and tissue blood flow.

\section{Experimental protocol}

Dogs $(n=24)$ were randomly assigned to receive halothane, isoflurane, or desflurane. All dogs were fasted overnight and fluid deficits were replaced before experimentation with crystalloid ( $500 \mathrm{ml} 0.9 \%$ normal saline). Maintenance fluids $(0.9 \%$ normal saline) were continued at $3 \mathrm{ml} \cdot \mathrm{kg}^{-1} \cdot \mathrm{hr}^{-1}$ for the duration of each experiment. Baseline haemodynamic variables were recorded and an injection of radioactive microspheres was completed in the conscious state. Inhalational induction was accomplished with desflurane, isoflurane, or halothane in $100 \%$ oxygen in different dogs in three separate experimental groups. After tracheal intubation, anaesthesia was maintained with each anaesthetic in a nitrogen (79\%) - oxygen (21\%) mixture. End-tidal anaesthetic concentrations of volatile anaesthetics were determined at the tip of the endotracheal tube with a mass spectrometer (Marquette Advantage 2000 , St. Louis, MO) for isoflurane and halothane or with an infrared anaesthetic gas analyzer (Datex Capnomac, Helsinki, Finland) specifically calibrated by the manufacturer for the detection of desflurane. Both the mass spectrometer and gas analyzer were calibrated using known standards prior to and during experimentation. Canine MAC values for desflurane, isoflurane, and halothane used in this study were $7.2,1.28$, and $0.86 \%$, respectively. Desflurane was delivered using a modified Ohio DM 5000 (Ohmeda, Madison, WI) anaesthesia machine, which incorporated a temperature-controlled vaporizer designed to provide uniform, predictable rates of desflurane vapour administration. Arterial blood gases 
were maintained at constant levels via adjustment of nitrogen and oxygen concentrations and respiratory rate throughout the experiment.

Anaesthetic concentrations were selected to produce equihypotensive effects. The low and high concentrations of each anaesthetic corresponded to decreases in mean arterial pressure of approximately 25 and $40 \mathrm{mmHg}$, respectively. After a 30-min equilibration period at either the low or high concentration (selected randomly) of each volatile anaesthetic, systemic and coronary haemodynamics were recorded and a second set of radioactive microspheres was administered. The concentration of the agent was then changed, and after a 30 min equilibration period, haemodynamic variables were again recorded and a final set of radioactive microspheres was administered. All dogs were euthanized with an overdose of sodium pentobarbital at the conclusion of each experiment. The heart, kidney, liver, intestine, and skeletal muscle were removed, washed with saline, and fixed for $48 \mathrm{hr}$ in a $10 \%$ formaldehyde solution prior to obtaining specimens for blood flow analysis.

\section{Statistical analysis}

A total of 29 dogs were used to provide 24 successful experiments. Five dogs were excluded due to instrument failure. Statistical analysis of data within and between groups during the conscious state and during all anaesthetic interventions was performed by analysis of variance (ANOVA) with repeated measures followed by application of Duncan's multiple range test. The changes from control within and between groups were considered statistically significant when the probability $(P)$ was less than 0.05 . All data are expressed as mean \pm SEM.

\section{Results}

The systemic and coronary haemodynamic effects of desflurane, isoflurane, and halothane are summarized in Tables I, II, and III, respectively. Desflurane anaesthesia produced an increase in heart rate and decreases in mean arterial pressure, left ventricular systolic pressure, and rate-pressure product $(P<0.05)$. A small increase in left ventricular end diastolic pressure was noted with both concentrations of desflurane. Global myocardial contractility, as assessed by left ventricular $\mathrm{dP} / \mathrm{dt}_{\max }$, decreased in a dose-related fashion with the administration of desflurane (2280 \pm 230 during control to $1130 \pm 90 \mathrm{mmHg} \cdot \mathrm{sec}^{-1}$ at the high dose, $P<0.05$ ). Regional myocardial contractility, as assessed by percent segment shortening, also declined. Diastolic coronary blood flow velocity did not change during desflurane anaesthesia but calculated diastolic coronary vascular resistance decreased (Table I).

Isoflurane produced systemic and coronary haemodynamic actions which were nearly identical to those produced by desflurane (Table II). Increases in heart rate and left ventricular end diastolic pressure and decreases in mean arterial pressure, left ventricular systolic pressure, ratepressure product, peak positive left ventricular $\mathrm{dP} / \mathrm{dt}_{\max }$, and percent segment shortening were observed with isoflurane. No change in diastolic coronary blood flow velocity but a decrease in relative diastolic coronary vascular resistance was observed with isoflurane anaesthesia, similar to the findings with desflurane.

TABLE I Systemic and coronary haemodynamic effects of desflurane

\begin{tabular}{lccc}
\hline & Conscious control & Low dose & High dose \\
\hline HR $(\mathrm{bpm})$ & $100 \pm 5$ & $132 \pm 8^{*}$ & $123 \pm 9^{*}$ \\
MAP $(\mathrm{mmHg})$ & $96 \pm 5$ & $69 \pm 3^{*}$ & $58 \pm 3^{*}$ \\
LVSP $(\mathrm{mmHg})$ & $129 \pm 4$ & $93 \pm 4^{*}$ & $77 \pm 3^{*}$ \\
LVEDP $(\mathrm{mmHg})$ & $7 \pm 1$ & $10 \pm 1^{*}$ & $10 \pm 2^{*}$ \\
RPP $\left(\mathrm{mmHg} \cdot \mathrm{bpm} \cdot 10^{3}\right)$ & $13.1 \pm 0.7$ & $11.1 \pm 0.8$ & $9.3 \pm 0.9^{*}$ \\
dP/dt & $\left(\mathrm{mmHg} \cdot \mathrm{sec}^{-1}\right)$ & $1560 \pm 160^{*}$ & $1030 \pm 90^{*}$ \\
DCBFV $\left(\mathrm{Hz} \times 10^{2}\right)$ & $37 \pm 5$ & $39 \pm 8$ & $31 \pm 7$ \\
DCVR $(\mathrm{ru})$ & $2.52 \pm 0.41$ & $1.87 \pm 0.41$ & $1.79 \pm 0.37^{*}$ \\
SS $(\%)$ & $20 \pm 3$ & $12 \pm 4^{*}$ & $12 \pm 3^{*}$ \\
pH (u) & $7.42 \pm 0.02$ & $7.40 \pm 0.02$ & $7.39 \pm 0.02$ \\
PCO $(\mathrm{mmHg})$ & $29 \pm 2$ & $28 \pm 2$ & $28 \pm 1$ \\
PO $(\mathrm{mmHg})$ & $83 \pm 2$ & $103 \pm 7^{*}$ & $104 \pm 6^{*}$ \\
ET(\%) & - & $8.0 \pm 1.1$ & $11.6 \pm 1.3$ \\
$\mathrm{MAC}^{2}$ & - & $1.11 \pm 0.12$ & $1.63 \pm 0.13$ \\
\hline
\end{tabular}

Mean $\pm \operatorname{SEM}$ data $(n=8)$.

*Significantly $(P<0.05)$ different from conscious control.

Abbreviations: $H R=$ heart rate; $M A P=$ mean arterial pressure; $L V S P$ and LVEDP = left ventricular systolic and end diastolic pressure, respectively; $R P P=$ rate-pressure product; $D C B F V=$ diastolic coronary blood flow velocity; DCVR = diastolic coronary vascular resistance; $S S=$ segment shortening; $E T=$ end tidal anaesthetic concentration; $\mathrm{MAC}=$ minimum alveolar concentration. 
TABLE II Systemic and coronary haemodynamic effects of isoflurane

\begin{tabular}{lccc}
\hline & Conscious control & Low dose & High dose \\
\hline HR $(\mathrm{bpm})$ & $98 \pm 9$ & $118 \pm 7^{*}$ & $108 \pm 6$ \\
MAP $(\mathrm{mmHg})$ & $100 \pm 6$ & $76 \pm 6^{*}$ & $64 \pm 4^{*}$ \\
LVSP $(\mathrm{mmHg})$ & $125 \pm 9$ & $97 \pm 8^{*}$ & $88 \pm 7^{*}$ \\
LVEDP $(\mathrm{mmHg})$ & $10 \pm 1$ & $10 \pm 2$ & $13 \pm 2^{*}$ \\
RPP $\left(\mathrm{mmHg} \cdot \mathrm{bpm} \cdot 10^{3}\right)$ & $12.2 \pm 1.8$ & $10.9 \pm 1.0$ & $8.7 \pm 0.6^{*}$ \\
dP/dt $\max \left(\mathrm{mmHg} \cdot \mathrm{sec}^{-1}\right)$ & $2430 \pm 300$ & $1580 \pm 130^{*}$ & $1280 \pm 10^{*}$ \\
DCBFV $\left(\mathrm{Hz} \times 10^{2}\right)$ & $37 \pm 4$ & $39 \pm 6$ & $35 \pm 5$ \\
DCVR $(\mathrm{m})$ & $2.57 \pm 0.29$ & $2.02 \pm 0.24$ & $1.78 \pm 0.26^{*}$ \\
SS Segment $(\%)$ & $18 \pm 3$ & $13 \pm 2^{*}$ & $11 \pm 2^{*}$ \\
pH $(\mathrm{u})$ & $7.42 \pm 0.01$ & $7.40 \pm 0.01$ & $7.40 \pm 0.01$ \\
PCO $(\mathrm{mmHg})$ & $28 \pm 1$ & $29 \pm 1$ & $31 \pm 1$ \\
PO & $(\mathrm{mmHg})$ & $149 \pm 25^{*}$ & $151 \pm 26^{*}$ \\
ET $(\%)$ & - & $1.6 \pm 0.2$ & $2.4 \pm 0.3$ \\
MAC & - & $1.22 \pm 0.14$ & $1.85 \pm 0.17$ \\
\hline
\end{tabular}

Mean \pm SEM data $(n=8)$

*Significantly $(P<0.05)$ different from conscious control.

Abbreviations: $H R=$ heart rate; $M A P=$ mean arterial pressure; $L V S P$ and LVEDP = left ventricular systolic and end diastolic pressure, respectively; RPP = rate-pressure product; $D C B F V=$ diastolic coronary blood flow velocity; DCVR = diastolic coronary vascular resistance; $S S=$ segment shortening; ET = end tidal anaesthetic concentration; $\mathrm{MAC}=$ minimum alveolar concentration.

TABLE III Systemic and coronary haemodynamic effects of halothane

\begin{tabular}{lccc}
\hline & Conscious control & Low dose & High dose \\
\hline HR $(\mathrm{bpm})$ & $96 \pm 6$ & $118 \pm 9^{*}$ & $109 \pm 8$ \\
MAP $(\mathrm{mmHg})$ & $105 \pm 2$ & $77 \pm 3^{*}$ & $63 \pm 3^{*}$ \\
LVSP $(\mathrm{mmHg})$ & $134 \pm 6$ & $98 \pm 4^{*}$ & $85 \pm 4^{*}$ \\
LVEDP $(\mathrm{mmHg})$ & $10 \pm 1$ & $10 \pm 1$ & $13 \pm 2^{*}$ \\
RPP $\left(\mathrm{mmHg} \cdot \mathrm{bpm} \cdot 10^{3}\right)$ & $12.2 \pm 0.8$ & $10.9 \pm 0.9$ & $8.5 \pm 0.9^{*}$ \\
dP/dt $t_{\max }\left(\mathrm{mmHg} \cdot \mathrm{sec}^{-1}\right)$ & $2790 \pm 230$ & $1520 \pm 140^{*}$ & $1040 \pm 90^{*}$ \\
DCBFV $\left(\mathrm{Hz} \times 10^{2}\right)$ & $44 \pm 7$ & $33 \pm 7^{*}$ & $29 \pm 5^{*}$ \\
DCVR $(\mathrm{ru})$ & $2.40 \pm 0.30$ & $2.74 \pm 0.49$ & $2.27 \pm 0.38$ \\
SS $(\%)$ & $16 \pm 4$ & $10 \pm 3^{*}$ & $7 \pm 3^{*}$ \\
pH $(\mathrm{u})$ & $7.42 \pm 0.02$ & $7.39 \pm 0.01$ & $7.38 \pm 0.02$ \\
PCO $(\mathrm{mmHg})$ & $30 \pm 2$ & $30 \pm 1$ & $30 \pm 2$ \\
PO $(\mathrm{mmHg})$ & $85 \pm 2$ & $172 \pm 78^{*}$ & $152 \pm 73^{*}$ \\
ET $(\%)$ & - & $1.2 \pm 0.2$ & $1.8 \pm 0.3$ \\
MAC & - & $1.44 \pm 0.13$ & $2.15 \pm 0.19$ \\
\hline
\end{tabular}

Mean \pm SEM data $(n=8)$.

*Significantly $(P<0.05)$ different from conscious control.

Abbreviations: $\mathrm{HR}=$ heart rate; $M A P=$ mean arterial pressure; $L V S P$ and $L V E D P=$ left ventricular systolic and end diastolic pressure, respectively; $R P P=$ rate-pressure product; $D C B F V=$ diastolic coronary blood flow velocity; DCVR = diastolic coronary vascular resistance; $\mathrm{SS}=$ segment shortening; $\mathrm{ET}=$ end tidal anaesthetic concentration; $\mathrm{MAC}=$ minimum alveolar concentration.

Halothane anaesthesia also caused an increase in heart rate and decrease in mean arterial and left ventricular systolic pressure (Table III). Global myocardial contractility $\left(\mathrm{dP} / \mathrm{dt}_{\max }\right)$ decreased in a dose-dependent fashion. In contrast to the findings observed with desflurane and isoflurane, administration of halothane produced doserelated decreases in diastolic coronary blood flow velocity. No change in calculated diastolic coronary vascular resistance were observed. Small increases in arterial oxygen tension $\left(\mathrm{PO}_{2}\right)$ were noted in all anaesthetized animals.

The effects of desflurane, isoflurane, and halothane on myocardial perfusion are summarized in Table IV. No changes in regional myocardial blood flow were observed during administration of desflurane in any region. Administration of isoflurane resulted in decreases in myocardial perfusion in the subepicardium, midmyocardium, and subendocardium at the high concentration. In contrast, 
TABLE IV Effects of desflurane, isoflurane and halothane on regional myocardial blood flow $\left(\mathrm{ml} \cdot \mathrm{min}^{-1} \cdot \mathrm{g}^{-1}\right)$

\begin{tabular}{llll}
\hline & Conscious control & Low concentration & High concentration \\
\hline $\begin{array}{l}\text { Desflurane } \\
\text { Subepicardium }\end{array}$ & $1.00 \pm 0.14$ & & \\
Midmyocardium & $1.53 \pm 0.24$ & $1.09 \pm 0.11$ & $0.92 \pm 0.11$ \\
Subendocardium & $1.55 \pm 0.24$ & $1.41 \pm 0.19$ & $1.25 \pm 0.19$ \\
Transmural & $1.36 \pm 0.20$ & $1.45 \pm 0.24$ & $1.26 \pm 0.22$ \\
Endo/epi & $1.55 \pm 0.06$ & $1.32 \pm 0.18$ & $1.15 \pm 0.17$ \\
& & $1.39 \pm 0.10$ & $1.33 \pm 0.14$ \\
Isoflurane & & & \\
Subepicardium & $1.14 \pm 0.15$ & & \\
Midmyocardium & $1.35 \pm 0.17$ & $1.02 \pm 0.12$ & $0.82 \pm 0.19^{*}$ \\
Subendocardium & $1.36 \pm 0.15$ & $1.19 \pm 0.17$ & $0.84 \pm 0.10^{*}$ \\
Transmural & $1.28 \pm 0.15$ & $1.17 \pm 0.14$ & $0.90 \pm 0.11^{*}$ \\
Endo/epi & $1.29 \pm 0.08$ & $1.12 \pm 0.14$ & $0.86 \pm 0.13^{*}$ \\
& & $1.17 \pm 0.08$ & $1.25 \pm 0.12$ \\
Halothane & & & \\
Subepicardium & $1.92 \pm 0.06$ & $0.70 \pm 0.08^{*}$ & $0.48 \pm 0.06^{*}$ \\
Midmyocardium & $1.31 \pm 0.10$ & $0.91 \pm 0.11^{*}$ & $0.69 \pm 0.08^{*}$ \\
Subbendocardium & $1.39 \pm 0.10$ & $0.93 \pm 0.08^{*}$ & $0.69 \pm 0.06^{*}$ \\
Transmural & $1.21 \pm 0.09$ & $0.85 \pm 0.09^{*}$ & $0.62 \pm 0.06^{*}$ \\
Endo/epi & $1.51 \pm 0.06$ & $1.37 \pm 0.09$ & $1.44 \pm 0.08$ \\
\hline
\end{tabular}

Mean \pm SEM data $(n=8$ for each agent)

"Significantly $(P<0.05$ ) different from "conscious control."

Endo/epi = ratio of subendocardial to subepicardial perfusion

halothane anaesthesia produced dose-related reductions in transmural blood flow across all subsections of the myocardium $(P<0.05)$. Neither low nor high end tidal concentrations of desflurane, isoflurane, or halothane produced a redistribution of intramyocardial blood flow as indicated by the ratio of subendocardial to subepicardial perfusion (endo/epi ratio).

A decrease in renal cortical blood flow was observed when desflurane was administered (Figure $1 ; 6.36 \pm 0.80$ during control to $5.45 \pm 0.53 \mathrm{ml} \cdot \mathrm{min}^{-1} \cdot \mathrm{g}^{-1}$ at the high concentration). Dose-related decreases in renal cortical blood flow were also observed during administration of halothane and isoflurane (5.37 \pm 0.56 during control to $3.90 \pm 0.63 \mathrm{ml} \cdot \mathrm{min}^{-1} \cdot \mathrm{g}^{-1}$ at the high dose of halothane and $5.45 \pm 0.55$ during control to $3.51 \pm 0.39$ $\mathrm{ml} \cdot \mathrm{min}^{-1} \cdot \mathrm{g}^{-1}$ at the high dose of isoflurane, respectively). Desflurane, but not isoflurane nor halothane, decreased calculated renal cortical vascular resistance $(17.5 \pm 2.5$ during control to $11.3 \pm 1.0 \mathrm{mmHg} / \mathrm{ml} \cdot \mathrm{min}^{-1} \cdot \mathrm{g}^{-1}$ at the high dose).

Administration of halothane caused a decrease in hepatic arterial blood flow at the high concentration. In contrast, desflurane and isoflurane tended to increase hepatic blood flow, although these increases did not reach the statistical significance (Figure 2). Concomitant decreases in hepatic artery vascular resistance were observed with both desflurane and isoflurane. No change in hepatic vascular resistance occurred during halothane anaesthesia. Blood flow to the duodenum decreased in a dose-related fashion during administration of halothane $\left(0.76 \pm 0.09\right.$ during control to $0.41 \pm 0.08 \mathrm{ml} \cdot \mathrm{min}^{-1} \cdot \mathrm{g}^{-1}$ at the high dose) and isoflurane (0.94 \pm 0.17 during control to $0.46 \pm 0.06 \mathrm{ml} \cdot \mathrm{min}^{-1} \cdot \mathrm{g}^{-1}$ at the high dose) but not desflurane (Figure 3). Perfusion of skeletal muscle also decreased during isoflurane and halothane anaesthesia but was preserved at both concentrations of desflurane (Figure 4).

\section{Discussion}

The effects of desflurane on systemic and coronary haemodynamics and regional tissue perfusion in the heart, kidney, liver, intestine and skeletal muscle were investigated and compared with those produced by equihypotensive end tidal concentrations of isoflurane and halothane in chronically instrumented dogs. Transmural myocardial perfusion was not changed during administration of desflurane. In addition, no redistribution of blood flow from subendocardium to subepicardium (endo/epi) was observed when desflurane was administered. Halothane and isoflurane, in contrast, reduced transmural myocardial perfusion in a dose-related fashion and at the higher anaesthetic concentration, respectively. These results require qualification, however, since left ventricular end diastolic pressure was lower in dogs anaesthetized with 


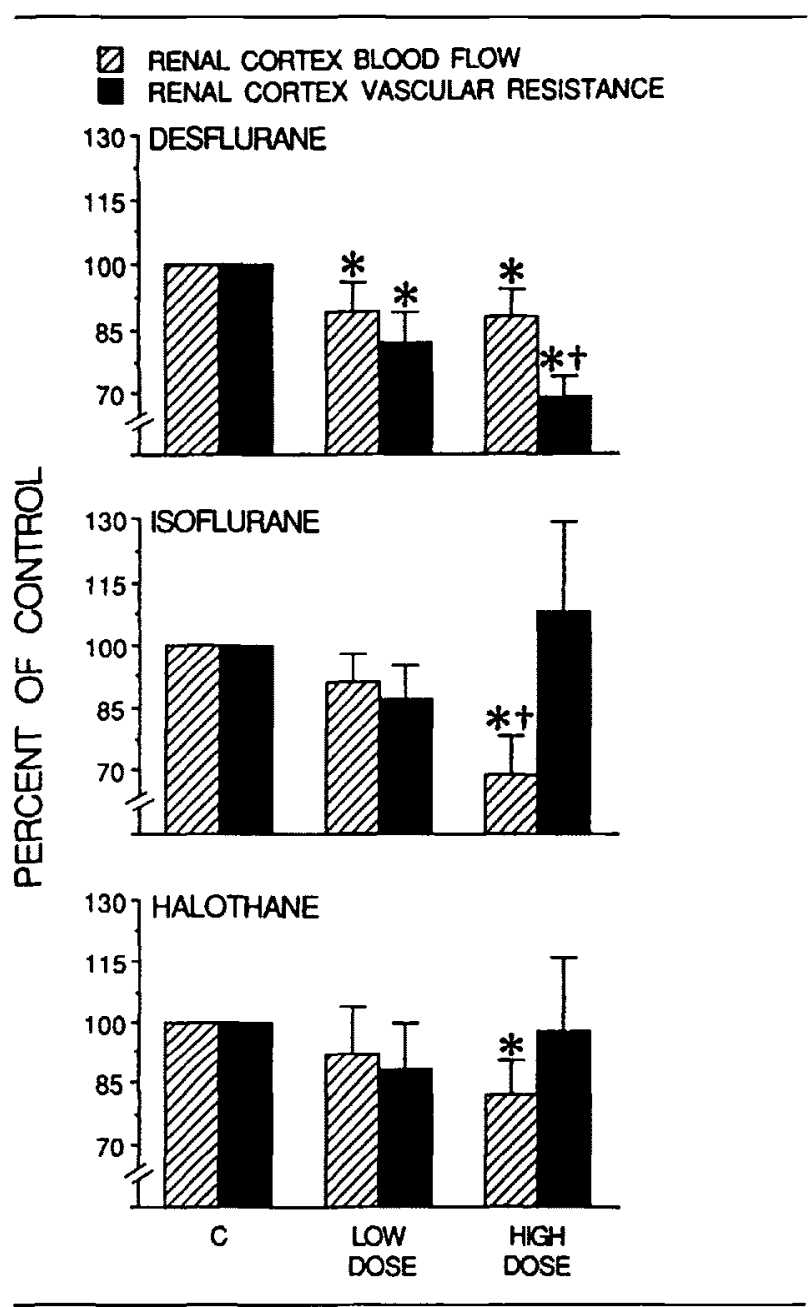

FIGURE 1 Histograms depicting the influence of low and high concentrations of desflurane, isoflurane, and halothane on renal cortical blood flow (hatched bars) and renal cortical vascular resistance (solid bars). Data are presented as a percent of control. *Significantly $(P<0.05)$ different from the conscious control $(C)$; $†$ Significantly $(P<0.05)$ different from the low concentration.

high-dose desflurane than in animals under high-dose isoflurane or halothane anaesthesia. This small difference in left ventricular end diastolic pressure between anaesthetic groups may have contributed to greater coronary perfusion pressure and enhanced subendocardial perfusion in the desflurane anaesthetized dogs. All three volatile anaesthetics reduced blood flow to the renal cortex; however, only desflurane produced a significant decrease in renal cortical vascular resistance. Halothane, but not desflurane or isoflurane decreased hepatic blood flow. Decreases in blood flow to splanchnic and skeletal muscle beds were also observed during administration of halothane and isoflurane but not desflurane. The results of the present investigation suggest that desflurane maintains myocardial, hepatic, duodenal, and skeletal muscle blood

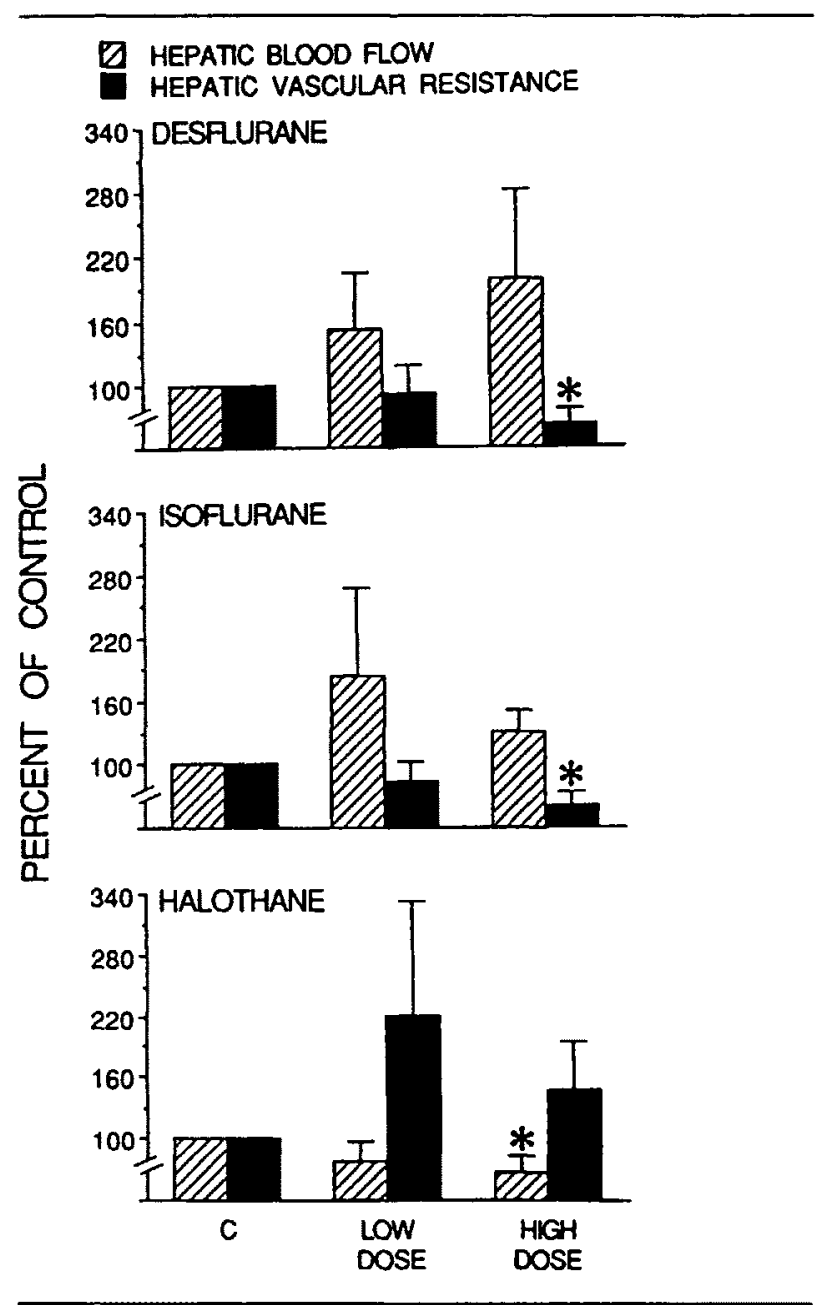

FIGURE 2 Histograms depicting the influence of low and high concentrations of desflurane, isoflurane, and halothane on hepatic blood flow (hatched bars) and hepatic vascular resistance (solid bars). Data are presented as a percent of control. *Significantly $(P<0.05)$ different from the conscious control (C).

flow. In contrast, halothane and isoflurane decrease regional tissue perfusion in these vascular beds to varying degrees.

Desflurane, a new inhalational anaesthetic, is a structural analogue of isoflurane, with a fluorine replacing the chlorine atom on the alpha ether carbon. Desflurane has attracted intense recent interest because it is the first new volatile anaesthetic to undergo clinical trials in the United States in almost $20 \mathrm{yr}^{16}$ Desflurane may have clinical advantages over presently used agents due in part to rapid induction and emergence characteristics ${ }^{8}$ combined with remarkable metabolic stability. ${ }^{9-12}$ The cardiovascular actions of desflurane have been extensively described in several recent reports from this ${ }^{3.13,17,18}$ and other laboratories. ${ }^{1,2,4-19}$ Desflurane has been shown to produce a 


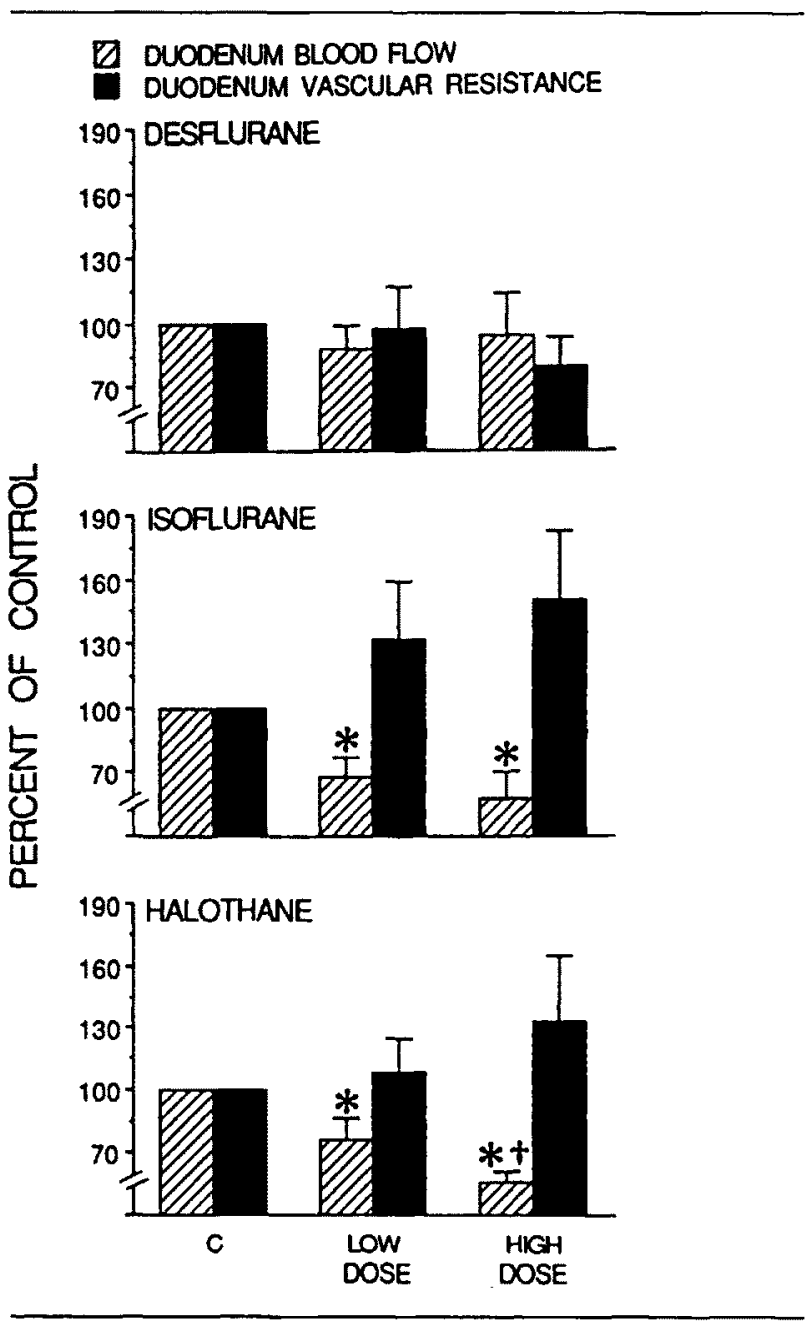

FIGURE 3 Histograms depicting the influence of low and high concentrations of desflurane, isoflurane, and halothane on duodenal blood flow (hatched bars) and duodenal vascular resistance (solid bars). Data are presented as a percent of control. *Significantly $(P<0.05)$ different from the conscious control $(C)$; $†$ Significantly $(P<0.05)$ different from the low concentration.

systemic haemodynamic profile which is very similar to that of isoflurane, although some studies ${ }^{3,5}$ indicate that desflurane may, in fact, produce less cardiodepressant effects than isoflurane at equianaesthetic (as assessed by MAC) concentrations. Despite the extensive descriptions of the actions of desflurane on cardiovascular function, the effects of this drug on regional tissue perfusion have yet to be thoroughly characterized. The present investigation used a radiolabelled microsphere technique to describe the effects of desflurane on regional myocardial tissue perfusion and regional blood flow in the renal, hepatic, splanchnic, and skeletal muscle vascular beds. The effects of desflurane on regional tissue perfusion were compared with those produced by equally hypotensive concentrations of halothane and isoflurane. This technique provided the

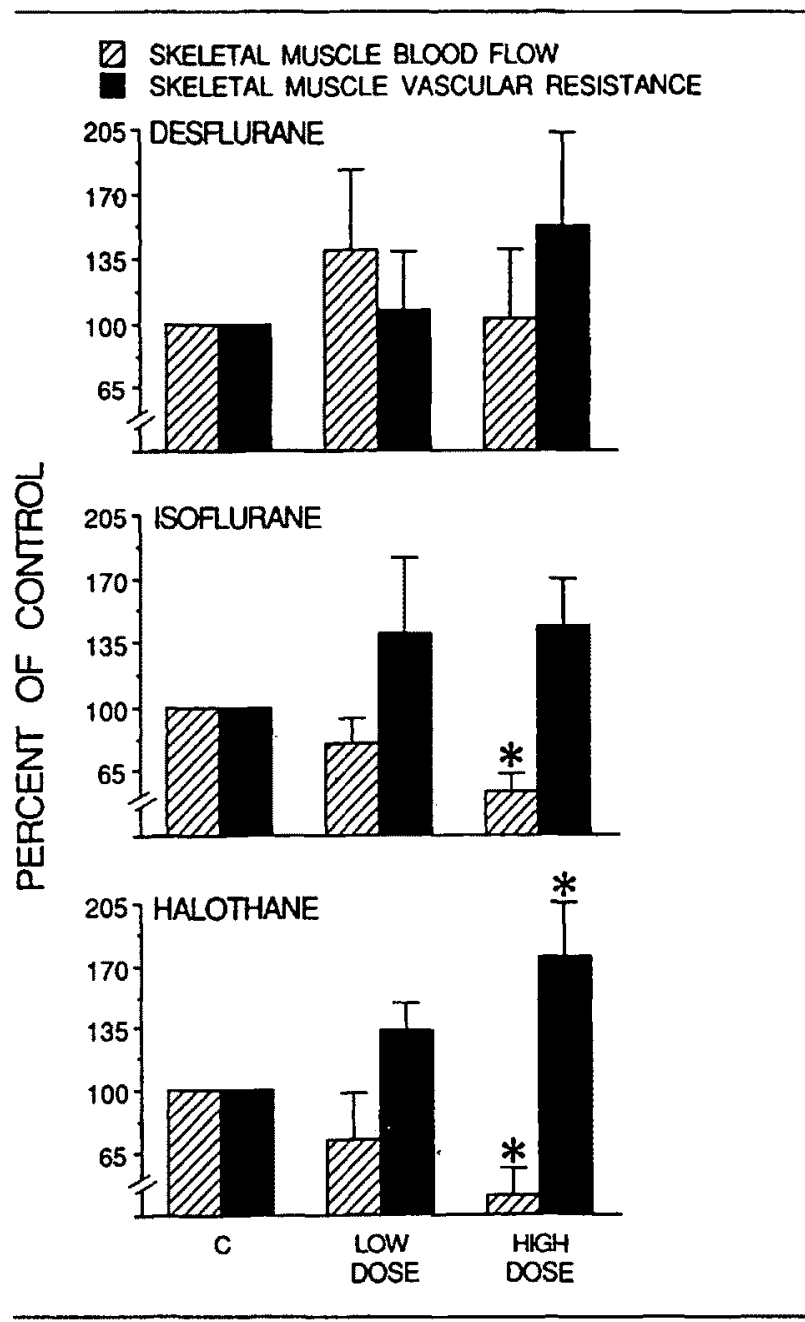

FIGURE 4 Histograms depicting the influence of low and high concentrations of desflurane, isoflurane, and halothane on skeletal muscle blood flow (hatched bars) and skeletal muscle vascular resistance (solid bars). *Significantly $(P<0.05)$ different from the conscious control (C).

advantage that a predefined decrease in a measured haemodynamic variable, mean arterial blood pressure, was used as the end point for comparison of regional blood flow between experimental groups. Anaesthetic-induced equivalent reductions in driving pressures to the tissues studied allowed comparisons of the direct effects of these agents on regional blood flow independent of perfusion pressure. In contrast, multiples of MAC were not chosen as a baseline for measurement since MAC strictly defines neurological, rather than haemodynamic, potency.

The effects of isoflurane and halothane on myocardial perfusion in the normal and obstructed coronary circulation have been previously described. ${ }^{20-25}$ Isoflurane has been intensely scrutinized because coronary vasodilatation has been reported during administration of this anaesthetic. ${ }^{24,26,27}$ Coronary vasodilatation may be associated with 
coronary steal in certain anatomic configurations of coronary artery obstruction ${ }^{28,29}$ However, results of studies performed in a variety of animal models of coronary artery obstruction and in patients with coronary artery disease have not conclusively demonstrated that administration of isoflurane is contraindicated in these settings. ${ }^{20-22,30,31}$ These results suggest that the coronary vasodilator activity of isoflurane may not be sufficient to redistribute blood flow away from ischaemic zones, in contrast to a more potent coronary vasodilator, such as adenosine. ${ }^{30}$ Desflurane, like isoflurane, may also possess coronary vasodilator activity. ${ }^{2,3} \mathrm{~A}$ recent investigation from this laboratory ${ }^{13}$ demonstrated that desflurane did not alter the regional distribution of coronary blood flow in a chronically instrumented canine model of multivessel coronary artery disease. These results were similar to those obtained when isoflurane was studied in an identical model. The actions of desflurane on the distribution of myocardial perfusion in the normal coronary vasculature were characterized in the present investigation. The present results suggest that desflurane maintains myocardial perfusion without transmural redistribution of flow, even during large decreases in perfusion pressure. Similar results were observed with isoflurane, implying that these two agents produce some degree of coronary vasodilation. In contrast, halothane produced dose-dependent decreases in regional myocardial blood flow, suggesting that this agent produces little, if any, coronary vasodilation. These conclusions should be qualified, however, because coronary autoregulation may dictate changes in coronary blood flow in response to alterations in myocardial oxygen demand. Although myocardial oxygen consumption was not specifically measured in this investigation, no differences in the rate-pressure product (an indirect indicator of myocardial oxygen consumption) were observed between groups, suggesting that desflurane, isoflurane and halothane produced similar alterations in myocardial oxygen demand.

Merin $e t$ al. $^{2}$ used Doppler ultrasonic flow transducers implanted on the renal and hepatic arteries to study the effects of desflurane and isoflurane on global blood flow to the kidney and liver. The authors demonstrated that these volatile agents preserved renal blood flow and produced concomitant decreases in renal vascular resistance, particularly at higher concentrations. The present investigation focused on the effects of volatile anaesthetics on perfusion of the renal cortex and demonstrated that desflurane, isoflurane, and halothane produce decreases in blood flow to this region of the kidney. Only desflurane, but not halothane or isoflurane, caused concomitant declines in renal arterial vascular resistance, partially supporting the findings of Merin et $a l^{2}$ when the entire kidney was considered. Maintenance of total renal flow may have occurred in this study if the volatile anaesthetics redistributed flow from cortical to medullary regions. The findings of the present investigation also suggest that desflurane and isoflurane, but not halothane, decrease hepatic vascular resistance. These results are also partially supported by the findings of Merin et al., ${ }^{2}$ who demonstrated declines in hepatic arterial resistance with isoflurane and suggested that desflurane may also decrease hepatic arterial resistance, although the latter conclusion was not verified. Several important differences between the present investigation and that of Merin et al., ${ }^{2}$ including the technique of blood flow measurement (radioactive microspheres versus ultrasonic flow transducers), regional versus global assessment of tissue perfusion, and substantially greater decreases in perfusion pressures encountered at higher anaesthetic concentrations in the present investigation, may partially contribute to the discrepancy in results obtained in these two studies. The effects of isoflurane on renal and hepatic blood flow demonstrated in the current investigation are also partially supported by several previous studies, ${ }^{32-37}$ although presence of baseline anaesthetics, acute surgical preparation and use of different animal species complicate direct comparison between these studies and the current investigation. Similar discrepancies also make comparison with previous studies examining the effect of halothane on hepatic blood flow difficult, although the present findings clearly support those of Gelman et al..$^{36}$ and Frink et al. ${ }^{37}$ who demonstrated decreases in hepatic arterial blood flow with halothane but not isoflurane in pentobarbital anaesthetized, acutely instrumented dogs (by the radioactive microsphere technique) and chronically instrumented dogs (using electromagnetic flow probes), respectively.

This investigation represents the first to examine specifically the effects of the desflurane on splanchnic and skeletal muscle blood flow. The results suggest that blood flow to the intestine and skeletal muscle is maintained during desflurane anaesthesia. In contrast, blood flow to these vascular beds is diminished to varying degrees during administration of halothane or isoflurane. Tranquilli et al ${ }^{32}$ demonstrated a decrease in small intestinal blood flow using radioactive microspheres when halothane was administered to chronically instrumented swine. Decreases in splanchnic blood flow have been observed during isoflurane anaesthesia in chronically instrumented lambs. ${ }^{35}$ Perfusion of the small intestine also was shown to be decreased in during administration of isoflurane and halothane in the study by Gelman $\mathrm{et} \mathrm{al} .{ }^{36}$ Other investigations examining the effect of isoflurane and halothane on skeletal muscle blood flow suggest that these agents produce decreases in perfusion in this vascular bed at higher concentrations. ${ }^{34,38}$

In summary, the effects of the new volatile anaesthetic, 
desflurane, on regional tissue perfusion have been shown to be distinctly different from those produced by halothane and isoflurane. Tissue perfusion in the heart, renal cortex, intestine and skeletal muscle may be better preserved with desflurane than with halothane or isoflurane when these anaesthetics are administered in equihypotensive doses in chronically instrumented dogs.

\section{Acknowledgements}

The authors extend their appreciation to John Tessmer, Doug Hettrick and David Schwabe for their technical assistance and Mimi Mick, Suzanne Emmrich and Jane Sikkenga for their assistance in the preparation of this manuscript. The authors are indebted to Anaquest, Murray Hill, New Jersey for supplying desflurane.

\section{References}

1 Weiskopf RB, Holmes MA, Eger EI II, Johnson BH, Rampil IJ, Brown JG. Cardiovascular effects of I-653 in swine. Anesthesiology 1988; 69: 303-9.

2 Merin RG, Bernard JM, Doursout MF, Cohen $M$, Chelly JE. Comparison of the effects of isoflurane and desflurane on cardiovascular dynamics and regional blood flow in the chronically instrumented dog. Anesthesiology 1991; 74: 568-74.

3 Pagel PS, Kampine JP, Schmeling WT, Warltier DC. Comparison of the systemic and coronary hemodynamic actions of desflurane, isoflurane, halothane, and enflurane in the chronically instrumented dog. Anesthesiology 1991; 74: 539-51.

4 Lutz $L J$, Milde $J H$, Milde $L N$. The cerebral functional, metabolic, and hemodynamic effects of desflurane in dogs. Anesthesiology 1990; 73: 125-31.

5 Weiskopf RB, Cahalan MK, Eger EI II, et al. Cardiovascular actions of desflurane in normocarbic volunteers. Anesth Analg 1991; 73: 143-56.

6 Cahalan MK, Weiskopf RB, Eger EI II, et al. Hemodynamic effects of desflurane/nitrous oxide anesthesia in volunteers. Anesth Analg 1991; 73: 157-64.

7 Weiskopf RB, Cahalan MK, Ionescu P, et al. Cardiovascular actions of desflurane with and without nitrous oxide during spontaneous ventilation in humans. Anesth Analg 1991; 73: 165-74.

8 Eger EI II. Partition coefficients of I-653 in human blood, saline, and olive oil. Anesth Analg 1987; 66: 971-3.

9 Koblin DD, Eger EI II, Johnson BH, Konopka K, Waskell $L$. I653 resists degradation in rats. Anesth Analg 1988; 67: 534-8.

10 Koblin DD, Weiskopf RB, Holmes MA, et al. Metabolism of I653 and isoflurane in swine. Anesth Analg 1989; 68: 147-9.

11 Eger El II, Johnson BH, Strum DP, Ferrell LD. Studies of the toxicity of I-653, halothane, and isoflurane in enzymeinduced, hypoxic rats. Anesth Analg 1987; 66: 1227-9.
12 Sutton TS, Koblin DD, Gruenke LD, et al. Fluoride metabolites after prolonged exposure of volunteers and patients to desflurane. Anesth Analg 1991; 73: 180-5.

13 Hartman JC, Pagel PS, Kampine JP, Schmeling WT, Warltier $D C$. Influence of desflurane on regional distribution of coronary blood flow in a chronically instrumented canine model of multivessel coronary artery obstruction. Anesth Analg 1991; 72: 289-99.

14 Theroux P, Franklin D, Ross $J J r$, Kemper WS. Regional myocardial function during acute coronary artery occlusion and its modification by pharmacologic agents in the dog. Circ Res 1974; 35: 896-908.

15 Domenech RJ, Hoffman JI, Noble MI, Saunders KB, Henson JR, Subijanto S. Total and regional coronary blood flow measured by radioactive microspheres in conscious and anesthetized dogs. Circ Res 1969; 25: 581-96.

16 Stevens WC, Cromwell TH, Halsey MJ, Eger EI II, Shakespeare TF, Bahlman SH. The cardiovascular effects of a new inhalation anesthetic, Forane, in human volunteers at constant arterial carbon dioxide tension. Anesthesiology $1971 ; 35: 8-16$.

17 Pagel PS, Kampine JP, Schmeling WT, Warltier DC. Influence of volatile anesthetics on myocardial contractility in vivo: desflurane versus isoflurane. Anesthesiology 1991; 74: 900-7.

18 Pagel PS, Kampine JP, Schmeling WT, Warltier DC. Alteration of left ventricular diastolic function by desflurane, isoflurane, and halothane in the chronically instrumented dog with autonomic nervous system blockade. Anesthesiology 1991; 74: 1103-14.

19 Milde $L N$, Milde JH. The cerebral and systemic hemodynamic and metabolic effects of desflurane-induced hypotension in dogs. Anesthesiology 1991; 74: 513-8.

20 Tarnow J, Markschies-Hornung A, Schulte-Sasse U. Isoflurane improves the tolerance to pacing-induced myocardial ischemia. Anesthesicology 1986; 64: 147-56.

21 Buffington $C W$, Romson $J L$, Levine A, Duttlinger NC, Huang $A H$. Isoflurane induced coronary steal in a canine model of chronic coronary occlusion. Anesthesiology 1987; 66: 280-92.

22 Cason BA, Verrier ED, London MJ, Mangano DT, Hickey RF. Effects of isoflurane and halothane on coronary vascular resistance and collateral myocardial blood flow: their capacity to induce coronary steal. Anesthesiology 1987; 67: 665-75.

23 Sivarajan M, Bashein $G$. Effect of halothane on coronary collateral circulation. Anesthesiology 1985; 62: 588-96.

24 Reiz S, Balfors E, Sorensen MB, Ariola S Jr, Friedman A, Truedsson $H$. Isoflurane - a powerful coronary vasodilator in patients with coronary artery disease. Anesthesiology 1983; 59: 91-7.

25 Khambatta HJ, Sonntag H, Larsen R, Stephan H, Stone $J G, \operatorname{Kettler} D$. Global and regional myocardial blood flow and metabolism during equipotent halothane and iso- 
flurane anesthesia patients with coronary artery disease. Anesth Analg 1988; 67: 936-42.

26 Blaise $G$, Sill JC, Nugent $M$, VanDyke RA, Vanhoutte PM. Isoflurane causes endothelium-dependent inhibition of contractile responses of canine coronary arteries. Anesthesiology 1987; 67: 513-7.

27 Becker $L C$. Is isoflurane dangerous for the patient with coronary artery disease? (editorial). Anesthesiology 1987; 66: 259-61.

28 Gross GJ, Warltier DC. Coronary steal in four models of single or multiple vessel obstruction in dogs. Am J Cardiol 1981; 48: 84-92.

29 Becker $L C$. Conditions for vasodilator-induced coronary steal in experimental myocardial ischemia. Circulation 1978; 57: 1103-10.

30 Hartman JC, Kampine JP, Schmeling WT, Warltier DC. Alterations in collateral blood flow produced by isoflurane in a chronically instrumented canine model of multivessel coronary artery disease. Anesthesiology 1991; 74: 120-33.

31 Hartman JC, Kampine JP, Schmeling WT, Warltier DC. Steal-prone coronary circulation in chronically instrumented dogs: isoflurane versus adenosine. Anesthesiology 1991; 74: 744-56.

32 Tranquilli WJ, Manohar M, Parks CM, Thurmon JC, Theodorakis MC, Benson GJ. Systemic and regional blood flow distribution in unanesthetized swine and swine anesthetized with halothane + nitrous oxide, halothane, or enflurane. Anesthesiology 1982; 56: 369-79.

33 Vatner SF, Smith NT. Effects of halothane on left ventricular function and distribution of regional blood flow in dogs and primates. Circ Res 1974; 34: 155-67.

34 Amory DW, Steffenson JL, Forsyth RP. Systemic and regional blood flow changes during halothane anesthesia in the rhesus monkey. Anesthesiology 1971; 35: 81-90.

35 Brett CM, Teitel DF, Heymann MA, Rudolph AM. The cardiovascular effects of isoflurane in lambs. Anesthesiology 1987; 67: 60-5.

36 Gelman S, Fowler KC, Smith LR. Regional blood flow during isoflurane and halothane anesthesia. Anesth Analg 1984; 63: 557-65.

37 Frink EJ, Morgan SE, Coetzee A, Conzen PF, Brown $B R$. The effects of sevoflurane, halothane, enflurane, and isoflurane on hepatic blood flow and oxygenation in chronically instrumented greyhound dogs. Anesthesiology 1992; 76: 85-90.

38 Lundeen $G$, Manohar $M$, Parks $C$. Systemic distribution of blood flow in swine while awake and during 1.0 and 1.5 MAC isoflurane anesthesia with or without $50 \%$ nitrous oxide. Anesth Analg 1983; 62: 499-512. 